\title{
Design Research and Art-Based Design Education Programs
}

\author{
Mejlhede, Dorthe
}

Document Version

Final published version

Published in:

Design Issues

DOI:

10.1162/DESI_a_00350

Publication date:

2015

Citation for published version (APA):

Mejlhede, D. (2015). Design Research and Art-Based Design Education Programs. Design Issues, 31(4), 44-55. https://doi.org/10.1162/DESI_a_00350

Link to publication in CBS Research Portal

\section{General rights}

Copyright and moral rights for the publications made accessible in the public portal are retained by the authors and/or other copyright owners and it is a condition of accessing publications that users recognise and abide by the legal requirements associated with these rights.

Take down policy

If you believe that this document breaches copyright please contact us (research.lib@cbs.dk) providing details, and we will remove access to the work immediately and investigate your claim. 


\title{
Design Research and Art-Based Design Education Programs
}

\author{
Dorthe Mejlhede
}

Journal article (Published version)

This article was originally published in Design Issues, Volume 31, No. 4, Pages 44-55.

First published online: October 6, 2015.

DOI: 10.1162/DESI_a_00350

Uploaded to Research@CBS: October 2015

Available at: http://research.cbs.dk/da/publications/design-research-andartbased-design-education-programs\%28ab12a721-29b0-4ad5-8189b614e7bd84c8\%29.html

(C) 2015 Massachusetts Institute of Technology

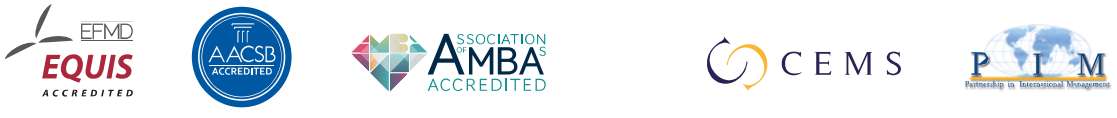




\section{Design Research and Art-Based Design Education Programs Dorthe Thorning Mejlhede}

\section{Introduction}

This article describes a model for establishing national design research and upgrading art-based design education programs at the university level. It aims to provide an overview of the development and achievements of design research in Denmark against a particular political, organizational, academic, and professional background during a ten-year period. Having served as the director of the Danish Centre of Design Research (DCDR) from 2007 to $2012,{ }^{1}$ I try, as objectively as possible, to review the background for the political decision to establish the Centre, its actual establishment, the research evaluation in 2010, and the closing of the Centre in 2012.

In 2000 the Danish Evaluation Institute presented an evaluation of the Danish design education programs under the auspices of the Danish Ministry of Culture. ${ }^{2}$ This evaluation, called Design 2000, recommended that research activities be established at the institutions of design education. Following the issuance of the evaluation report, the Danish Parliament decided to found the DCDR in 2003. The DCDR's purpose was to support the establishment of a joint design research capacity for the four Danish institutions offering design education programs: Aarhus School of Architecture (ASA), The Danish Design School (DDS), Kolding School of Design (KSD), and the Royal Danish Academy of Fine Arts, School of Architecture (RDA/SoA). The plan included a scheduled research evaluation in 2010, which would serve as the basis for a decision about the future of the DCDR, design research in Denmark and the organization of it. The evaluation was carried out as scheduled and gave a highly favorable assessment of the

In 2008, the design research center was renamed Danish Centre for Design Research (DCDR) in order to be more visible internationally.

2 The report unfortunately is only accessible in Danish. Translations of the quotations from the report into English in this article are mine.

3 The DDS and RDA/SoA merged in 2011 into The Royal Danish Academy of Fine Arts, Schools of Architecture, Design and Conservation (RDA/SoADC).
DCDR's achievements.

After the general election in 2011, both the DCDR and the design education programs were transferred to the Ministry of Education and Research, which oversees the other institutions of higher learning in Denmark. In 2012, the Danish government decided to close the DCDR and reallocate its annual grant of DKK 3.6 million to the three partner institutions. (Two of the original four had merged in 2011.3) 
The article proceeds as follows: In the next section, I examine the DCDR's development through the 1990s in terms of its research potential (rather than the education programs, enrollment criteria, etc.), looking at selected aspects of research. In the following section, I describe the establishment of the DCDR in 2003, its mid-term evaluation and reconstruction in 2006. In the third section, I review the research evaluation in 2010 and the perspectives it introduced. Because the establishment, existence, and closing of the DCDR are so closely related to developments in Danish politics, the article examines the political scene and the constellation of political factors behind the DCDR's founding and closing, offering a brief epilogue about the influence of politics on design.

\section{Prologue: The Political Arena and the Design Environment}

In the late 1990s, the Ministries of Business Affairs and Culture launched a number of joint design policy initiatives. Following up on these initiatives, Parliament decided to evaluate the design education programs that were located under the Ministry of Culture. This decision marked the culmination of a political focus on design that had lasted throughout the 1990s.

Similar design research developments occurred during the same period at the Danish universities under the auspices of the Danish Ministry of Research. The universities played an important role for the design schools, which had begun to hire teaching staff from the universities. The schools now wanted to establish their own, practice-oriented design research and were somewhat skeptical of the growing emphasis on theory and academics in design. In addition, some concern emerged for the future of the craft aspect, along with the fears that future generations of designers would fail to learn proper craftsmanship and that computer technology would drive out traditional crafts and furniture design. At the same time, the field maintained a certain distance from the field of architecture, which viewed design as a subordinate discipline to architecture. In this multi-disciplinary environment, with its many actors and conflicting interests, political initiatives led to the development of a new design research environment.

\section{The 1999 Evaluation of Design Education Programs}

In 1999 five educational institutions under the auspices of the Ministry of Culture provided design education to practitioners: They included the ASA, DDS, KSD, and RDA/SoA, as well as the Glass and Ceramics School on Bornholm. After the Danish Evaluation Institute evaluated the design programs at the five institutions, it included the first four-but excluded the Glass and Ceramics School on Bornholm-as partner institutions to the DCDR when it was founded in 2003. The purpose of the evaluation was to assess the quality of the design programs and the schools' 
4 Design 2000: 15. Note that this preliminary definition of the concept of design is defined in more detail in the section titled "The Concept of Design."

5 Ibid.

6 Ibid.

7 The report discusses, among other things, the differences in the schools' profiles, cooperative relations, and distribution of tasks and recommends that the schools "develop more distinct profiles for their programs and, for the schools of architecture, also for their research in the field of design." Design 2000: 19.

8 Ibid., 25.

9 lbid.

10 Ibid., 26. The original reference is Herbert Simon, The Sciences of the Artificial (Cambridge, MA; London, England: The MIT Press, 1969), 58-59.

11 Ibid. research potential. I focus on the latter goal in this section because the DCDR was established to support the development of research activities.

The report notes that the five programs under the Ministry of Culture are very diverse, reflecting the diversity of the Danish design profession. The architecture programs tend to view design as "processes that take place in relation to space," while the design schools emphasize their "firm roots in craftsmanship, the technical and artistic approach to materials as the essential point of departure for form-giving and product development."

The evaluation report views this diversity as positive, seeing it as promoting an "honest and functionalist design tradition, which has become a characteristic of Denmark." ${ }^{5}$ However, the report also points out "the urgent need to make a deliberate and targeted effort to create a renewed and integrated development" in a society where the designer's role is undergoing dramatic transformation. The report's discussion and explanation of the concepts of design and research are central in the foundation of the DCDR. I examine them briefly here before turning to the report's assessments of and recommendations for research. ${ }^{7}$

\section{The Concept of Design}

The report emphasizes the multiplicity of design definitions. On the one hand, the most widespread definition, which also corresponds to the meaning of the English word, is "to shape or give form." In a narrower definition, design means "giving form to industrially produced products"—also known as product design. The report also compares the definition of design in the Danish government's design report- “Design is the expression of a creative process that integrates the physical properties of a product with aesthetic concerns" ${ }^{\prime \prime}$ - with the design definition that prevails in the architectural education programs, where it is viewed as an "aspect of architecture that prioritizes type over site." ${ }^{\prime 9}$ The report examines Nobel laureate Herbert Simon's conceptualization of design, in which he compared it to the natural sciences: Where science is "concerned with how things are," design is "concerned with how things ought to be, with devising artifacts to attain goals." ${ }^{\prime 10}$ The evaluation team's goal was not to set or prioritize one specific definition of design over the others but "to draw attention to the very diverse perceptions of the design concept." Still, the report continues, "it seems clear that design is about a deliberate process of form-giving with both physical and aesthetic aspects." ${ }^{11}$

The report also notes the differences between the perceptions of design in the design schools vs. perceptions in the schools of architecture: Materials and craftsmanship are the key basis of form-giving and product development in the design schools, while the schools of architecture view design mainly as 
spatial processes. "[T]hese programs exist in a society that is characterized by an ever-faster pace of change in the perception of what constitutes a product, what creates value for the customers, and what the underlying processes should be."12 In addition, products are made in different materials than those traditionally used by craftspeople, and they are consumed in a global marketplace. If a designer's presumed core competence is to understand and design products for an "uncertain future context," the team's findings were seen as posing a challenge to the existing programs and their transformation: "[T]he schools viewed information technology mostly as a new tool to be used in the same processes rather than a factor that implies changes in the design process itself."13 The report concluded that the schools only to a limited extent had tried to transform the design profession.

The Concept of Research

Regarding "research," the report draws a clear distinction between "scientific research" and "artistic development work." It defines the former as "a cognitive goal; that is, its purpose is to collect and develop new knowledge about its particular domain." ${ }^{14}$ Meanwhile, it defines artistic development work as:

... processes that reflect the creative process from the perspective of the artistic creative process itself- "from within," so to speak, with the purpose of developing and qualifying this process. Artistic development work thus aims to qualify artistic production [... and] documents its own preconditions and contains a reflection on the artistic creative process in all its components..$^{15}$

In their general assessments of research in relation to design education, the evaluation team concluded that theory courses heavily emphasized art history and material properties, among other topics, while in the architectural programs, the theoretical emphasis was on architectural theory. The team called for research and theories that relate more directly to the design discipline:

(...) there appears to be a large unmet need for developing domain-specific research and theories that take a more in-depth approach in order to promote a more profound understanding of the fundamental methodology and practice of the design process. Not least considering the rapid change that we see in society's expectations of the designers' competences. ${ }^{16}$

12 Ibid.

13 Ibid., 27.

14 Ibid., 36.

15 Ibid., 37.

16 Ibid., 43

The evaluation team also recommended that the design schools develop a research capacity, including drawing up strategies for recruiting researchers in cooperation with the schools of architecture and other educational institutions in Denmark. Cooperation between the design schools and the schools of architecture should 
include both the research aspects and the workshop and craft aspects of design training. The team recommended that a national research committee be established to distribute research funds based on applications from the design education programs, with the purpose of improving the design schools' ability "to become research institutions." ${ }^{17}$ The committee, it suggested, would serve as "a natural platform for increasing cooperation among the design education programs in Denmark." ${ }^{18}$

\section{Cooperation with Other Educational Institutions}

The evaluation report addressed the need for cooperation with other educational institutions, both in Denmark and abroad. For example, it suggested a cross-institutional cooperation beyond the Ministry of Culture which involved the ASA, Aalborg University, and the Technical University of Denmark. However, the DDS's self-evaluation produced in relation to Design 2000 pointed out that future research would require national collaboration on research education and that, "the missing research status of the school might give a certain asymmetry in its cooperation with institutions that have research status." ${ }^{\prime 19}$ In the past, this non-research status had forced the school to abandon certain joint projects.

The evaluation team recommended that the design programs improve the international exchange among teaching staff and students by placing a higher priority on inviting guest teachers from abroad and encouraging students to include studying abroad in their degree plans. Finally, the evaluation team recommended that DDS and KDS organize stays-abroad for their teaching staff, such as teaching opportunities and study leaves.

In summary, the 2000 report from the Danish Evaluation Institute focuses on the rather heterogeneous approach to design education at the four schools, the inadequate theoretical and methodological foundation for the design discipline, the research potential at DDS and KDS and thus the need to establish research education, and the lack of cooperation among the educational institutions as well as the need for internationalization.

Ibid., 44.

8 Ibid.

19 Design 2000, 106

20 In 1999 in Bologna (Italy), 29 European ministers of education agreed to establish a common framework for university programs within Europe. The universal European system is now defined as 3 years +2 years +3 years (Bachelor, Master and $\mathrm{PhD}$ degrees). See the official website for the Bologna Process: http://www.ehea.info/ /(accessed August 15, 2013).

\section{The Founding of the DCDR}

The DCDR was officially founded on June 17,2003 , based on a parliamentary agreement in 2002. This agreement was part of the government's action plan, titled "Better Educations," which aimed to raise the quality of the educational programs under the Ministry of Culture and ensure stable economic conditions for the programs from 2003 through 2006. The agreement was backed by all the parties in Parliament. A basic condition was that the area would be spared budget cuts, and in return the schools would initiate positive developments in their respective fields. As a requirement, the programs had to adhere to the Bologna declaration, ${ }^{20}$ with a $3+2$ 
21 The geographic distribution of activities was maintained, so that design researchers who worked at the KSD formally joined the staff of the ASA, while design researchers who worked at the DDS formally joined the staff of the RDA/SoA in Copenhagen. academic degree structure to ensure the students' ability to transfer credits both within Denmark and internationally. The parliamentary agreement specifically mentioned design research. With reference to a 2000 report on culture and business policies, Denmark's Creative Potential, it highlighted design as an area with a particularly strong growth potential. To realize this potential, Danish design research needed a lift.

The agreement required initiatives and funding to establish binding research collaborations among the schools of design and architecture to create a shared competence center for Danish design research. Another goal of the agreement was to establish professorships and PhD programs in the field of design based on binding cooperation agreements among the schools of design and architecture or between these schools and other research-based higher education institutions.

The agreement led to the founding of the DCDR, as marked by the founding memorandum of June 2003, with September 1, 2003 as the specified start-up date. The four schools had established a cooperation agreement under which the schools of architecture, which already had the academic staffing structure in place, made this structure available to the two design schools so that these schools could add researchers to their staff, with the DCDR as an intermediary. ${ }^{21}$ Through this agreement, the two schools of design that did not have an academic staffing structure were able to establish research units.

The detailed and lengthy founding memorandum described the background, purpose, tasks, and organization of the DCDR, as well as the economic aspects of the cross-institutional cooperation. Among other tasks, the DCDR was to collect and disseminate knowledge about the design research at the participating schools, coordinate and initiate research projects, contribute to the development of research talents under the university staffing structure, and establish cooperation on a national and an international basis. It was to be led by a steering committee comprising the rectors of the four institutions and two international design research experts appointed by the Ministry of Culture. According to the memorandum, the participating schools were to be equal partners. In addition to the steering committee, the DCDR was to have a coordination committee and a director to oversee daily operations.

The memorandum also specified budgets for the schools from 2003 through 2006, including how many researchers each school would be contributing with, and the cost of professorships, associate professorships, assistant professorships, PhDs, and other staff members. Also included was each school's annual investment in design research from 2003 through 2006. Importantly, the agreement stressed that the Ministry of Culture would not cut the institutions' budgets if they invested in design research. The memo 
therefore specified each school's monetary contribution each year. In addition, funds for the DCDR's establishment, development, and operations were allocated in the national budget. ${ }^{22}$

\section{Mid-Term Evaluation and Reconstruction}

When the DCDR was founded, the agreement called for a midterm evaluation in 2006. This evaluation found that the DCDR was not operating at an optimal level. In 2006 the Ministry of Culture therefore appointed a new external chairman of the DCDR's steering committee and constructed a new set of statutes. I was appointed as new director Spring 2007, bringing new management and leadership competences and operating more independently from the schools and from the existing ideas about design and design research. After the reorganization, the director no longer actively conducted research but focused exclusively on management and leadership. The development of research activities was delegated to the four institutions. The DCDR office was reorganized around four teams with specific responsibilities: facilitating the development of research, offering a master's program, disseminating new research, and handling management and administration. (The master's program has been running since 2005, though.) An independent research committee was established comprising independent, external design researchers to assist management and the steering committee review research applications based on a set of guidelines. Applications were reviewed three times annually. After the review meetings, project funds were allocated from a basic government grant. Through the research committee, the DCDR distributed $\$ 2,823,747$ (DKK 19.2 million) in grants to new research projects. From 2003 to 2011, more than 70 research projects at the participating institutions were initiated and funded by the research grants managed by the DCDR on behalf of the Ministry of Culture. The application decisions were included in the steering committee meeting minutes to ensure transparency in the academic design environment.

\section{Post-2007 Developments}

After the reorganization, the DCDR office staff included one research associate professor. (Other researchers who had been employed at the DCDR office were transferred to the research

22 The DCDR received a total grant of $\$ 735,000$ (DKK 5 million) in 2003. This amount was set to grow to $\$ 2,794,333$ (DKK 19 million by 2006), at which point, according to the memo, the activities were to be evaluated before the agreement expired in 2006. A large part of this money was allocated to the DCDR from the schools budget, thus forcing them to invest in research. units at the individual schools.) In addition to being responsible for the master's program, the research associate professor actively researched and supported the efforts of the DCDR office to develop research capacity and activities in and across the participating schools.

Beginning in 2004, the DCDR invited all the schools' design researchers to an annual research conference, at which topics such as research-based education and design theory were addressed in 
23 Ida Engholm, "Master's Degree in Design - Research-Based Master's Program for Professional Designers," Nordic Journal of Architectural Research 20, no. 2 (2008): 105-11. Following the closure of the DCDR, the RDA/SoADC is now providing and managing the program.

24 See Artifact's website: http://scholarworks.iu.edu/journals/index.php/artifact/ index (accessed August 15, 2013). Artifact became an open-access journal in cooperation with Indiana University in the United States in 2011.

25 Mind Design was launched in 2007 as a magazine for design research. It was published ten times annually, each with at least three journalistic articles on design research; 54 issues were published in Danish and English: http:// www.dcdr.dk/uk/menu/update/webzine (accessed August 15, 2013).

26 For an overview of $\mathrm{PhD}$ projects in the field by January 2013, see: http://www. dcdr.dk/uk/menu/research/research-projects/projects (accessed August 15, 2013). presentations by the researchers from the DCDR environment as well as by experts in other research environments in Denmark and abroad. The DCDR also provided a framework for courses, seminars, and workshops for the researchers and PhD scholars.

The postgraduate Master of Design program was developed in 2005 as a part-time post-graduate education program based on user fees. Over the course of four semesters, the program addresses the design process (when design takes place), design management and distribution (Design Management) and design in context (Design and Meaning). The fourth semester is dedicated to the master's dissertation. ${ }^{23}$ The program is aimed at practicing designers, and during the DCDR's lifetime, 46 designers earned the academic title Master of Design; after the closure of the DCDR, 33 students graduated in June 2013.

After 2007, the DCDR developed an active and visible communication platform for research dissemination in Danish and English. In addition to its website, which provided information about its activities and organization, the DCDR published a monthly webzine on design research in Danish and English, as well as the annual publication Insights into Danish Design Research; it was also responsible for the research journal, Artifact. ${ }^{24}$

After the reorganization, the cooperation among the institutions in the DCDR's coordination committee was revitalized. Tasks in general were exchange of experiences, coordination of, and mutual information about research initiatives. Some tasks were, though, addressed external relations. For instance, the coordination committee drew up a research profile for the DCDR's research, Design for All, in cooperation with Invest in Denmark, the Ministry of Foreign Affairs' unit for promoting Denmark abroad. The profile outlined the value base of the research, as defined by the research and education environment; among these values were user involvement, sustainability, and the aesthetic qualities of materials and products.

\section{Research Quality and the Concept of Design}

The DCDR's webzine, Mind Design, became a platform for the exchange of knowledge among the researchers at the four partner institutions. ${ }^{25}$ In addition, Mind Design became a source for new knowledge on design for practitioners and the public in general. The webzine covered important seminars and conferences in text and images and initiated discussions of key topics, including the conceptualization of design. "Quality of Design Research" was the topic of the research seminar in 2007. Here, researchers from the DCDR environment shared reflections on the quality of research conducted in a practice field. ${ }^{26}$ The challenges involved accommodating the unique character of design research as a knowledge generator for a professional practice while bringing design research on the same level as university research in other 
27 Danish Centre for Design Research, Copenhagen, "Passing the Baton," Mind Design 1, no. 4 (2007), http://www.dcdr. $\mathrm{dk} / \mathrm{uk} / \mathrm{menu} / \mathrm{update} /$ webzine/articles/ passing-the-baton-4 (accessed August 15, 2013).

28 Dorthe Mejlhede, "Editorial: Danish Design Research Has Reached Good International Standard," Mind Design 4, no. 33 (2010), (See links to the evaluation reports in the bottom of the article.) http://www.dcdr.dk/uk/menu/update/ webzine/articles/danish-design-researchhas-reached-good-international-standard (accessed August 15, 2013). disciplines-not least out of consideration for future research funding needs because design research has to be able to compete with university research for funding from national research councils, private foundations, the European Union, and other sources. During the next few years, the design research discipline grew, and the many new $\mathrm{PhD}$ scholars made important contributions to the annual research conference, shared and exchanged knowledge, and helped build relationships across the institutions. From 2004 through 2012, DCDR distributed funds to 73 research projects based on applications submitted to the committee. The grants included three-month-long, so-called pre-doc grants, as well as partial funding for $\mathrm{PhD}$ or post-doc projects.

Mind Design also initiated debates between practitioners and researchers-for example, in a series of articles called "Passing the Baton," researchers and practitioners shared their views on design and the expanded concept of design before passing the baton on to another researcher or practitioner of their own choice. ${ }^{27}$

\section{The 2010 Evaluation}

An evaluation of the DCDR and the research it engendered was conducted in 2010. The Ministry of Culture established an evaluation panel that issued five reports after visiting the four schools and the DCDR office. The reports stated that design research in Denmark had "mainly been of very good, and in some areas excellent, quality," and the panel concluded that development in design research had made rapid and admirable progress since $2003 .{ }^{28} \mathrm{In}$ addition, the reports recognized that the idea of establishing a common entity like the DCDR to support and promote research is unique, and that it had played an important role in the development of design research.

In the fifth, general report, the evaluation panel offered recommendations regarding the continued cooperation among the schools, and the services required a common unit as the DCDR office. The research now met international standards, and the evaluation panel argued that it had a potential for further maturation in the coming years. Although the four schools were becoming more self-sustaining research units, their research environments were still rather small. Thus, joint research efforts and activities seemed a natural focus for the schools. The reports recommended that additional services be considered, including research lobbying and a help-desk for applications to national and international research foundations; it also recommended the promotion of a broader design research landscape by inviting institutions outside the area covered by the Ministry of Culture to join the network.

The panel also evaluated the PhD education being offered in the design research environment and concluded that the doctoral schools lacked sufficient volume and content to ensure qualified PhD education. In addition to those activities, the DCDR - on 
29 As of 2011 Denmark had still no new doctoral education for design, See Trine Vu, “Designers Need Design Specific PhD Courses" Mind Design 4, no. 40 (2011), http://www.dcdr.dk/uk/menu/update/ webzine/articles/designers-need-designspecific-phd-courses (accessed August 15 2013)

30 The Minister of Culture during the years from 2010 to 2012 chose not to follow the recommendations of the evaluation panel in paying more grants to the design research. Instead he focused among other things on developing a new radio station (Radio 24/7) within the Danish broadcasting field, which became $\$ 117,656,120$ (DKK 800 million) over an eight year period financed by the state.

31 After the efforts to develop and evaluate design research, the schools were charged with the task of developing and standardizing concepts and practices within artistic development work. average- had held one week-long $\mathrm{PhD}$ course per year. These $\mathrm{PhD}$ courses received a positive evaluation from the panel, which recommended that both a doctoral school for design and a joint administration and practical organization for doctoral education be established. ${ }^{29}$ The evaluation panel further recommended a review of the basic funding system for the design field and suggested an increase in the grant sum to reflect the political emphasis on design as a key area of future innovation. ${ }^{30}$

\section{Perspectives on DCDR's Results}

Denmark's two design schools acquired university status in a relatively short amount of time because of a strong political consensus and willingness to act and because of the level of cooperation among the four schools, facilitated by a fifth entity, the DCDR. The evaluation report from 2000 criticized the schools for their lack of homogeneity, a lack of consensus about the conceptualizations of design, and the lack of an actual theoretical and methodological foundation. Now after a ten year period, the design schools' research development have the capacity for developing sustainable research environments that can contribute to the methodological and theoretical development of design research, and the art-based educational institutions that train design practitioners provide coherent design research environments. These Danish research environments are rooted in an international design research environment and thus have a strong basis for contributing to the education of designers who can take on the future challenges facing society. Furthermore, the research environments at the art-based educational institutions draw a clear distinction between the concept of artistic development activities and scientific research, ${ }^{31}$ which enables them to enter into symmetrical partnerships with other research institutions.

In 2000, the evaluation criticized the lack of consistency in the schools' conceptualizations of design, but since then, the development of a research capacity has led to a much greater diversity of design genres and thus widespread recognition of the breadth of the field of design (although claiming any consensus about the expanded concept of design would be inaccurate), as well as a far more sophisticated design theory foundation represented by design researchers in the schools. Design education and research are no longer based exclusively on either art history or architectural theory, as the criticism went in 2000. Instead, the field has contributed to a theoretical and methodological platform for design that has allowed the research environments to work in depth and breadth with the various knowledge forms in design research. It not only has embraced the research concepts established by the Organization for Economic Co-operation and 
Development (OECD), but it also has established education programs in accordance with the Frascati Manual according to the Bologna Process. ${ }^{32}$

The design research environment and the design education programs at the art-based design education institutions in Denmark are much stronger today than they were ten years ago. The field now has a research capacity that enables the programs to address the ongoing changes and challenges in companies and society. Thanks to this development, the two design schools are now able to enter into symmetrical partnerships with other universities. Furthermore, the research has helped refine design practice, and the traditional perceptions of design have expanded and diversified. Thus, we now have a language for discussing immaterial design genres: service design, strategic design, co-design, design management, organizational design, and systems design. These design genres have emerged from the design and architecture programs and in turn constitute a source of language and methods that are useful in practical innovation processes. The fact that these disciplines have been able to gradually develop theories to match their practice and education programs strengthens their relevance to other disciplines and professions. For example, the substantial knowledge of and experience with processes that design research has generated are useful in the development of processes related to strategy and organization in business colleges.

The minister for education, research, and innovation closed the DCDR at the end of 2012, basing the decision on the government's policy on deregulation and on the successful completion of the DCDR's mission to promote design research. During its lifetime, the DCDR approved more than 70 research projects, distributing a total of $\$ 2,823,747$ (DKK 19.2 million). The projects approved in 2010 and 2011 continue to be supported and are handled by the new merged school, the RDA/SoADC. ${ }^{33}$

\section{Epilogue: Politics}

In the political arena, throughout the DCDR's tenure, the Ministry of Culture was headed by a variety of ministers and guided by varying political agendas. These shifts in directions and priorities affected the context for the DCDR's work over the years. In 2010, the government established a committee to draw up a design vision for Denmark in 2020. The committee's report, The Vision of the Danish Design 2020 Committee, which was released in 2011, envisions a situation where design research is well-coordinated and plays a leading role in the development of society. After the general election in 2011, the new government established a number of "Growth Teams" under the Ministry of Business and Growth, including a team charged with making recommendations for fund the remaining ongoing projects, which was scheduled to be completed in 2014 and 2015 
34 In spring 2013, the Growth Team made several recommendations to the government. The ones regarding education and research recommended that Denmark build strong education and research environments in the field of design and thus establish mechanisms that motivate national collaborations instead of competitiveness.

35 "The All-Party Parliamentary Design and Innovation Group" was organized by "Policy Connect" in the British Parliament. See http://www.policyconnect.org.uk/network/all-party-parliamentary-design-innovation-group (accessed August 15, 2013).

36 Mr. Brian Mikkelsen, of the Conservative People's Party.
"Creative Industries and Design." ${ }^{34}$ The current Danish government has no specific design policy but pursues a broader innovation policy that includes design among other areas.

Looking back at the 10- to 15-year effort to strengthen Danish design education, research, and the need for strong and dedicated politicians and ministers to focus on and support the multi-disciplinary field of design education and research is clear. This fact was acknowledged in the United Kingdom with the founding of The Association of Parliamentary Design and Innovation Group (APDIG) in 1994. APDIG is a formalized forum for dialogue among Parliament, government, and educational institutions in the field of design, business, and industry, aimed at promoting an understanding of the potential of design. Among other activities, APDIG generates knowledge that enables political decisionmakers to address design policy from a qualified, informed basis and thus secures the continuity of design policy. ${ }^{35}$ It would be natural to establish a similar political entity to secure continuity and a qualified knowledge base among the policymakers in Denmark.

In addition, the issue of personal political influence should not be overlooked. For eight years, the DCDR operated in relationship to a Minister of Culture who had a clear focus on design as a source of growth. ${ }^{36}$ The minister also held a key position in the Danish government, and his seat on important government committees gave him a strong platform for influencing government agendas and decisions.

By their very nature, research development processes, which deal with new challenges and take a long time to fully unfold, are vulnerable to political changes, including the replacement of ministers and other key political decision-makers. In its ten-year existence, the DCDR operated alongside a background of varying political alliances (center-left, center-right, and then center-left again). During that time, four different ministers led the Ministry of Culture, to which the design schools reported throughout most of the period. When the schools of design and architecture were moved to the Ministry of Education and Research after the 2011 general election, the government and the new (fifth) minister responsible for that area had other political agendas than continuing the former government leaders' policy on design. 